in psychiatric patients. A few of them may be mentioned: the Buss-Durkee Hostility Inventory with its sub-scales including 'physical aggression' (Buss \& Durkee, 1957) or the Brown-Goodwin assessment for lifetime history of aggression (Brown et al, 1979). Assessment and classification of such complex phenomena as aggression should not be based on only one scale, especially in genetic studies with their substantial clinical and possibly forensic/legal implications. Nevertheless, we hope that this research may provide more insight into the biological mechanisms underlying aggression.

Brown, G. L., Goodwin, F. K., Ballenger, J. C., et al (1979) Aggression in humans: correlates with cerebrospinal fluid amine metabolites. Psychiatry Research, I, |3|-139.

Buss, A. H. \& Durkee, A. (1957) An inventory for assessing different kinds of hostility. Journal of Consulting Psychology, 2I, 343-349.

Jones, G., Zammit, S., Norton, N., et al (200I) Aggressive behaviour in patients with schizophrenia is associated with catechol-O-methyltransferase genotype. British Journal of Psychiatry, 179, 35I-355.

Monahan, J., Steadman, H. J., Appelbaum, P. S., et al (2000) Developing a clinically useful actuarial tool for assessing violence risk. British Journal of Psychiatry, I76, 312-319.

Sanders, J., Milne, S., Browne, P., et al (2000) Assessment of aggression in psychiatry admissions: semistructured interview and case note survey. BMJ, 320,1112

Schanda, H. \& Taylor, P. (200I) In-patient violence: frequency, risk factors, preventive strategies (in German). Fortschritte Neurologie Psychiatrie, 69, 443-452.

Soyka, M. \& Ufer, S. (2002) Aggression in schizophrenia: prevalence, psychopathological and sociodemographic correlates (in German). Fortschritte Neurologie Psychiatrie, in press.

Steadman, H. J., Mulvey, E. P., Monahan, J., et al (1998) Violence by people discharged from acute psychiatric inpatient facilities and by others in the same neighborhoods. Archives of General Psychiatry, 55, I-9.

_ , Silver, E., Monahan, J., et al (2000) A

classification tree approach to the development of actuarial violent risk assessment tools. Law and Human Behavior, 24, 83-100.

Swanson, J.W., Swartz, M. S., Borum, R., et al (2000) Involuntary out-patient commitment and reduction of violent behaviour in persons with severe mental illness. British Journal of Psychiatry, 176, 324-331.

Yudofski, S. C., Silver, J. M., Jackson, W., et al (1986) The Overt Aggression Scale for the objective rating of verbal and physical aggression. American Journal of Psychiatry, 143, 35-39.

Wallace, C., Mullen, P., Burgess, P., et al (1998) Serious criminal offending and mental disorder. Care linkage study. British Journal of Psychiatry, I72, 477-484.

M. Soyka Psychiatric Hospital, University of Munich, Nußbaumstr. 7, 80336 München, Germany; e-mail: Michael.Soyka@psy.med.uni-muenchen.de

\section{Post-traumatic stress disorder and management of stillbirth}

Lovett (2001), commenting on our article 'Incidence, correlates and predictors of post-traumatic stress disorder in the pregnancy after stillbirth' (Turton et al, 2001) took issue with our reporting a possible association between post-traumatic stress disorder and holding the dead infant which did not reach statistical significance.

We should like to make two points. First, we were at pains to make it clear that numbers were small and not significant statistically. Second, although your correspondent could not know this at the time of writing, we have subsequently published a paper reporting a significant relationship between seeing the dead infant and disorganisation of mother-infant attachment in the next-born child at the age of 12 months (Hughes et al, 2001). This was an unexpected finding for us.

Our main concern is that a profound change in clinical practice (seeing and holding the dead infant) was introduced with great enthusiasm in maternity units in the UK and elsewhere on the basis of limited and non-systematic clinical observation. Our published findings to date do not offer any evidence in support of this practice. We concur with Dr Lovett that this is an area which demands further investigation and rigorous evaluation.

Hughes, P., Turton, P., Hopper, E., et al (200I) Disorganised attachment behaviour among infants born subsequent to stillbirth. Journal of Child Psychology and Psychiatry, 42, 791-801.

Lovett, K. F. (200I) PTSD and stillbirth (letter). British Journal of Psychiatry, 179, 367.

Turton, P., Hughes, P., Evans, C. D. H., et al (200I) Incidence, correlates and predictors of post-traumatic stress disorder in the pregnancy after stillbirth. British Journal of Psychiatry, I78, 556-560.

P. Turton, P. Hughes Parent Child Research Group, Department of Psychiatry, Jenner Wing, St George's Hospital Medical School, London SWI7 ORE, UK

\section{Psychiatric morbidity and elderly offenders}

While I agree entirely with Fazel et al (2001) that there is an unmet need for psychiatric care for elderly offenders, I wonder whether this need is even greater than is implied by their paper. It is important not to forget those elderly people who do not actually end up in prison but have committed crimes. Yorston (1999) notes that the elderly are less likely than younger offenders to have custodial sentences or fines imposed and are more likely to receive probation orders. Lynch (1988) postulated that the public's sympathy for the perceived frailty of the elderly is likely to lead to this group being treated more leniently. Bergman \& Amir (1973) have also noted a tendency for families to hide deviance, which may lead to offending behaviour in this group being underreported.

One revelation to me which emerges from Fazel et al's paper was the relatively high number of offenders imprisoned for drug offences (29/203). Older studies (e.g. Taylor \& Parrott, 1988) suggested that drug-related crime was of a much lower incidence: indeed, in their study of elderly custodial remand prisoners none aged 55 and over had been charged with a drugrelated offence, although they noted that misuse of alcohol appeared to rise steadily with age. I wonder whether Fazel et al are showing us that the victims of the drugs culture, traditionally thought to have been established in the UK in the 1960s, are now starting to feature among the elderly?

Bergman, S. \& Amir, M. (1973) Crime and delinquency among aged in Israel. Israel Annals of Psychiatry and Related Disciplines, II, 33-48.

Fazel, S., Hope, T., O’Donnell, l., et al (200I) Hidden psychiatric morbidity in elderly prisoners. British Journal of Psychiatry, 179, 535-539.

Lynch, S. (1988) Criminality in the elderly and psychiatric disorder. A review of the literature. Medicine, Science and the Law, 28, 65-78.

Taylor, P. J. \& Parrott, J. M. (1988) Elderly offenders. A study of age-related factors among custodially remanded prisoners. British Journal of Psychiatry, 152 , 340-346.

Yorston, G. (1999) Aged and dangerous. Old age forensic psychiatry. British Journal of Psychiatry, 174, 193-195.

A.Thompsell Maudsley Hospital, Denmark Hill, London SE5 8AZ, UK

Elderly mentally disordered offenders are underresearched and poorly understood, but Fazel et al (2001a) demonstrated high levels of 'hidden' psychiatric morbidity in a sample of male prisoners over 60 years of age.

The cases of the former Chilean dictator Augusto Pinochet and of Ernest Saunders, involved in the Guinness financial affair, illustrated the inherent difficulties of the older person in the forensic setting. 